\title{
FINANCE VERSUS COSTS FOR TEACHING HOSPITALS IN SPAIN
}

Guillem López-Casasnovas

Professor of Economics

Department of Economics, Pompeu Fabra University, Spain

Ramón Trias Fargas

Marc Saez

Associate Professor of Econometrics

Department of Economics, University of Girona,

Corresponding author:

Marc Saez, Department of Economics, University of Girona, Campus de Montilivi, 17071

Girona, Spain. Phone 34-72-41.87.36, Fax 34-72-41.80.32, e-Mail: msaez@gnomics.udg.es

\section{Acknowledgements}

We are grateful to the participants of the Workshop in Applied Economics at University Pompeu Fabra and of the Sixth European Workshop on Econometrics and Health Economics, Lisbon, Portugal, where a previous version of the paper was presented. Usual disclaimers apply. Guillem López-Casasnovas acknowledges financial support from the DGICYT under the project PB94-0848. 


\section{Summary}

In this paper we analyse the observed systematic differences in costs for teaching hospitals (TH henceforth) in Spain. Concern has been voiced regarding the existence of a bias in the financing of TH's has been raised once prospective budgets are in the arena for hospital finance, and claims for adjusting to take into account the 'legitimate' extra costs of teaching on hospital expenditure are well grounded. We focus on the estimation of the impact of teaching status on average cost. We used a version of a multiproduct hospital cost function taking into account some relevant factors from which to derive the observed differences. We assume that the relationship between the explanatory and the dependent variables follows a flexible form for each of the explanatory variables. We also model the underlying covariance structure of the data. We assumed two qualitatively different sources of variation: random effects and serial correlation. Random variation refers to both general level variation (through the random intercept) and the variation specifically related to teaching status. We postulate that the impact of the random effects is predominant over the impact of the serial correlation effects. The model is estimated by restricted maximum likelihood. Our results show that costs are $9 \%$ higher (15\% in the case of median costs) in teaching than in nonteaching hospitals. That is, teaching status legitimately explains no more than half of the observed difference in actual costs. The impact on costs of the teaching factor depends on the number of residents, with an increase of $51.11 \%$ per resident for hospitals with fewer than 204 residents (third quartile of the number of residents) and $41.84 \%$ for hospitals with more than 204 residents. In addition, the estimated dispersion is higher among teaching hospitals. As a result, due to the considerable observed heterogeneity, results should be interpreted with caution. From a policy making point of view, we conclude that since a higher relative burden for medical training is under public hospital command, an explicit adjustment to the extra costs that the teaching factor imposes on hospital finance is needed, before hospital competition for inpatient services takes place.

Keywords: Cost functions; semi-parametric estimation; regression analysis; teaching hospitals; prospective payments. 


\section{1.- Introduction.}

Some recent experiments in health system reforms (1) seem to offer some support for splitting responsibilities between finance and production in health service provision. In addition, whenever possible, some authors advocate simulating market competition amongst producers. The goal is that money should follow the patient, independently of the provider that the patient chooses, breaking the otherwise usual feature that 'money sticks on health services where it hits'. Since output based prospective budgeting defines reimbursement as a purchase of activity, the current missing link appears: a budget must be inserted as an activity based contract.

However, competition requires market prices, and these do not exist in health care. Cost efficiency tariffs need to be postulated instead. This is not an easy task, as cost per unit is not well known in hospital services. Efficiency estimation needs to account for scope and scale economies and other aspects related to the nature of the hospital output. Hospitals run multiproduct production functions, with care and cure activities, plus research and training. This mix does not usually show a similar 'bundling' for pure public hospitals and for other hospitals publicly financed hospitals. Therefore, hospital tariffs need to be corrected according to this output difference, without falling into the dangers of fully retrospective cost reimbursement. Finally, hospital unit costs are not always the result of managerial choice but can be the result of planning decisions taken by the health authority in the past. Sunk costs and social burdens may also be present to a variable extent.

In this paper we analyse the observed systematic differences in costs for teaching hospitals in Spain. We first analyse (in Section 2) the various strategies for TH adjustment by surveying the more significant literature on hospital cost functions, and in Section 3 we describe how different countries finance university hospitals in practice. In Section 4 we go on summarise what studies have to say about the impact of teaching status on average costs in Spain. After discussing the main caveats of these studies, we use a version of a multiproduct hospital cost function, assuming a flexible form for each of the explanatory variables. It includes both 
parametric (linear or non-linear) and non-parametric functions of the predictors. We also model the underlying covariance structure of the data, and two qualitatively different sources of variation: random effects and serial correlation. This is done in Section 5. Section 6 shows the results of the estimation, by adopting restricted maximum likelihood techniques. Finally, in Section 7, we offer a word of caution on the application of our results and on the implementation of hospital competition from a policy making point of view.

\section{2.- The teaching adjustment.}

Two strategies have been proposed for adjusting to take the teaching factor into account in hospital running costs: a) an allowance in the payment 'numeraire': usually a fee increase related to $\mathrm{TH}$ activity (inpatient admissions, outpatient visits, casualty, etc.). That is, extra TH costs are compensated by activity levels only; and b) a lump sum is paid for the 'stand by' factors related to teaching (and usually research), independently of the type of activity. Only for those who believe that the teaching factor is well explained by case-mix differences and fully compensated by differences in tariffs, with THs showing a higher capability to treat more complex patients, will teaching adjustments not be needed.

For compensating proposals non linear contracts (2) that break down the payment into a fixed and a variable component may help to solve both the efficiency (the prospective tariff) and the equity problem (being fair to the reimburse). But this combined strategy ultimately comes to depend on the relative weights of the two components. Under this approach, not surprisingly, pure public hospitals with a large vector of adjusting factors aim for a higher fixed and stable component, whereas 'non-pure' public hospitals strongly favour higher variable weights. In addition, the latter position pushes for internal 'contestable' markets with a higher competitive pressure on activity and hence on risk.

Literature on hospital cost estimation has again followed two different strategies in empirical studies. First of all, there are those focusing on efficient ways of classifying hospitals, in order to make comparisons. This is usually done by (i) taking variables related to the 
hospital licensing status and 'ex ante' planning for health care facilities, or by (ii) regarding 'ex post' the type of activities actually performed, through subsamples derived by homogeneous grouping or grade of membership techniques (3-4). For each of the resulting groups, the observed differences in average costs are attributed to the omitted variables, and in particular to the teaching effect.

A second approach consists of analysing additional marginal hospital costs due to the impact, other things being equal, of teaching activities. There is no 'a priori' reason for postulating the final sign of the teaching effect on costs. Firstly, higher costs may be due simply to higher wages. This is not always the case, since part of the staff salaries may be paid by the education (and not the health) authority. Moreover, a more complex case-mix may be the implicit cost increasing factor, reflected in greater intensive care activity and longer stays. However, direct costs are not always related to activity, as in the case of salary and fringe benefits for residents and teaching physicians, conference and classroom space, additional equipment, supplies, etc. Even after case-mix adjustment, indirect costs may result from increased diagnostic testing, number of procedures performed or greater supporting capacity. On the other hand, relative wages for residents are lower than average, without productivity necessarily being the case. This may reduce the overall impact of teaching programs on costs. A different strategy is to take the number of residents as the 'numeraire' for financing the structural component cost. However, higher costs may not follow a continuous function. This may be the case even when we adjust for the number of beds. As a result, a differential adjustment according to the ratio of residents per bed may also be needed. Ultimately, some additional questions may refer to whether the adjustment applies not only to inpatient activity, but also to outpatient, casualty and other specific programmes

In the following section we will summarise some of the approaches already utilised in adjusting for the teaching factor in hospital finance; basically, the cases of the UK and USA, these being compared to the present Spanish system. From this experience we will argue for improving the present adjustment by exploring the results of estimating a cost function using 
semi-parametric techniques for a sample of Spanish hospitals during the years 1987 to 1994.

\section{3.- How different countries finance university hospitals.}

In the United Kingdom, an explicit Service Increment for Teaching has been included in the resource distribution formula since 1978 (RAWP). Initially, S.I.F.T. involved the coverage of three quarters of the observed difference between the actual average costs of teaching versus comparable non-teaching hospitals. In 1989, 100\% of the difference was covered, but a quarter of this was formally attributed to research. In 1995 the extra financing was split between the Service Increment for Teaching and the Service Increment for Research and Development (S.I.F.R.D.), but without a prefixed formula. Undergraduate and postgraduate training is exclusively financed by the NHS.

In the United States, the DRG environment finance Medicare since 1983. Operating and capital indirect costs are included in tariffs. Direct costs have been included by Medicare since even earlier. In addition, the general tariffs are different according to the location of the hospital and territorial relative costs. The teaching adjustment applies to these tariffs. The hospital teaching load is financed by $8 \%$ of the overall Medicare budget. In 1992 this meant a $7.65 \%$ for each 0.1 resident per bed. At the Veteran Hospital Administration 45\% of the existing beds belong to teaching hospitals. A previous study by the Government Accounting Office (1989) computed for Medicare hospitals an extra cost per patient of $9.5 \%$ for a major teaching hospital (more than 0.25 residents per bed or more) with respect

to the average value of a non-teaching hospital. The regression estimates by GAO for all USA hospitals range from an extra cost of $3.73 \%$ to $7.19 \%$ of the average cost per patient (depending on the specification of different models), for each resident per bed. The estimated average value given by the Congressional Budget Office was 5\% higher than that of the hospital population as a whole. A recent survey of the literature on $\mathrm{TH}$ costs functions can be found in (5-6).

In Spain, medical schools are reparate from hospitals although linked by a specific agreement. The 
university authority finances the direct costs of the undergraduate training (mainly the teachers' salaries) and the Department of Health covers the direct costs of the postgraduate training programme ('in-job training') of the physicians, once they have passed the examinations enabling them to practise in the National Health System. Indirect costs are financed from the general hospital budgets. Direct costs for research are financed by the General and Health Research Agencies (CICYT and FISS, respectively). Indirect costs seem to be incorporated again into overall hospital budgets. There is a licensing system for medical training, currently awarded to $70 \%$ of public hospitals (and a few private ones), although one quarter of them they do not have specific agreements with medical faculties.

\section{4.- What do studies say about the impact of Spanish TH's on average costs?.}

In the above mentioned context, it should now be clear that we cannot identify any particular component of finance as TH costs. Given that full costs are unknown we must estimate them by comparing the cost structure (i) of teaching versus non-teaching hospitals, and (ii) individual hospitals in the first group, according to the size of the training programmes, once adjusted for the other remaining factors. The net costs of teaching are the result of the difference between the lower wages of junior physicians and higher costs from the training related activities.

López-Casasnovas estimated through Weighted Least Squares techniques the impact of teaching on average cost per patient for a sample of Spanish hospitals (7). By using a dummy variable and holding the same structural parameters (as Feldstein (8) pioneered) for teaching and non-teaching hospitals he sought to isolate the teaching factor. For this purpose, a behavioural deterministic function was postulated (residuals were assumed to reflect inefficiency). The impact of the teaching status increased the average predicted costs by $17 \%$. However, the assumption of identical functional form and the structural stability hypothesis, when we constrain teaching and non-teaching hospitals to an identical estimation could not be accepted. This provided the basis for a breakdown of the sample into two subsamples and predicted values of average costs being compared for both subsamples. 
By replicating the exercise for 1993, González did not obtain, at the ordinary levels of confidence, statistically significant coefficients for the DV on teaching status. Wagstaff obtained a similar result for a 1977-81 panel, by estimating in this case a cost frontier model with Generalised Least Squares methods (9). In more recent estimations, LópezCasasnovas and Wagstaff estimated, for a 1982 to 1986 panel, a positive and statistically significant coefficient for the teaching status, with values of between $8 \%$ and $15 \%$ (depending on the type of specified model) above the average cost per patient (10). However, when the estimation was repeated for the period 1984-88, the estimated coefficient did not seem to be robust enough. An attempt to find a better case-mix adjustment left the sample with just 38 hospitals. Given this, and some other potential collinearity problems, the above result could be explained.

Quintana, following the initial approach of López-Casasnovas and Wagstaff (11), estimated the impact of teaching status with a sample of 34 hospitals for the period 1984-88. Quintana's estimation seems to support an increase in the teaching factor, with a higher average cost per patient of $8.4 \%$, although Quintana's poor case-mix adjustment may conceal important misspecification errors.

Finally, two more recent studies yielded an impact on average cost of $3.1 \%$ and $11.1 \%$ (1213). The first one was based on 75 INSALUD (State administered) hospitals for the 1991 to 1993 period, and it estimated a cost frontier model, although with a relatively poor case-mix adjustment. The second study referred to 43 Catalan hospitals for the 1988 to 1991 period and it estimates an stochastic cost frontier with case-mix variables derived from the Information Theory (14). In both cases, the main purpose was not TH estimation but overall inefficiency estimation.

In brief, we may conclude that the range of variation for the estimated parameter is similar to that observed in other studies from different countries (Gaynor and Anderson (15) is for this purpose an exception. They estimated for 5000 USA hospitals an additional TH impact of just $1.4 \%$ on average costs per patient ). For instance, Culyer et al. estimated the extra 
cost for an English TH as being 15\% (16). By estimating different models, Zuckerman et al. valued the impact of teaching status on costs at between $8.1 \%$ and $15.3 \%$ (17). This last paper differentiates teaching hospitals according to the number of residents per bed (as opposed to simply taking a single DV). This approach was followed recently by González and Barber for INSALUD 1995 hospitals, refining the case-mix adjustment (DRG based) and utilising OLS techniques (18). Their results are: average costs -other things such as size and output characteristics being equal- are 3.6\% higher than average for hospitals with fewer than 20 residents (although the parameter here was not statistically significant); $14.1 \%$ for TH's with between 20 and 49 residents; 18.6\% (between 50 and 199) and 35.2\% for the few hospitals with more than 200 residents.

In this paper we will focus on the estimation of the impact of teaching status on average cost, taking into account all possible causes of the differences in results: the type of model, the actual specification of the model, the estimation techniques, the case-mix adjustment (a potentially correlated factor with hospital size and teaching status) and the type of training programmes considered (mainly postgraduate) and by excluding some specialities that are not strongly hospital based.

\section{5.- Model specification and variable definitions.}

Following López-Casasnovas and Wagstaff (13) we used a version of a multiproduct hospital cost function (19) in order to estimate the TH impact, since it has the advantage, among others, of not imposing a particular structure for the economies of scope and scale, if any

$$
\log \left(C_{h t}\right)=f\left(S D_{h t}, H_{h t}, E_{h t}, S_{h t}, A_{h t}, C A S E M I X, T E A C H_{h}\right)+\varepsilon_{h t}
$$


We estimated an average cost function in which Cht denotes operating costs of hospital $\mathrm{h}$ at time t; $\mathrm{SD}_{\mathrm{ht}}$ supply and demand variables; $\mathrm{H}_{\mathrm{ht}}$ hospital activity variables; $\mathrm{E}_{\mathrm{ht}}$ variables related to emergency activity; $S_{h t}$ surgical variables; $A_{h t}$ ambulatory variables; CASEMIX $X_{h}$ case-mix adjustment; and $\mathrm{TEACH}_{\mathrm{h}}$ those variables related to teaching status. The term $\varepsilon_{\mathrm{ht}}$ represents random variation. The sub-indexes denotes $\mathrm{h}$-th hospital $(\mathrm{h}=1,2, \ldots, 64)$ and year $\mathrm{t}$ $(\mathrm{t}=1992, \ldots, 1995)$.

Our data refer to 64 INSALUD public hospitals, 37 teaching and 27 non-teaching, for the years 1992-1995. The cost variable C, for each hospital and period, includes all current and capital outlays. These are converted to 1992 pesetas using the health care price index and divided by the number of hospital admissions. The price index is based on the evolution of the main components of public health expenditure, weighted by their respective shares. The health care index in the general cost of living deflator cannot be used for these purposes since it includes only private health care expenditure (mostly drugs).As the supply and demand variables, we consider the number of beds per thousand inhabitants and the number of total visits again per thousand inhabitants; the length of stay in days, the annual turnover index and the necropsy index included, as are some other hospital activity variables. The turnover index is defined as the number of hospital admissions divided by the number of beds. While the daily number of urgent surgical interventions is the variable related to emergency activity, our surgical variable is the daily (workdays) number of programmed surgical interventions per operating theatre. Finally, the daily (workdays) number of magnetic resonances and of the lithotrix sessions are the variables considered to be related to outpatient activity.

For the inpatient case-mix complexity variable we follow López-Casasnovas and Wagstaff (13). The case-mix complexity score was based on the US Patient Management Category (PMC) system. Discharges were grouped into PMC's according to the resource-intensity of care received by a typical patient in each discharge group. PMC's were then assigned weights according to their usage of resources. The case-mix index was then a weighted average of PMC scores, the weights being the case-mix proportions. As variables related to 
teaching activity we use a dummy variable indicating teaching status ( 1 if hospital is a teaching hospital, 0 otherwise) and the number of residents at the hospital. As they were available only for 1995, the last year of our study, we assumed that case-mix and teaching variables were time-invariant. This was later checked in practice.

We assume that the relationship between the explanatory and the dependent variables, $\mathrm{f}()$, has a flexible form for each of the explanatory variables. It may include both parametric (linear or non-linear) and non-parametric functions of the predictors. Among all the nonparametric possibilities we tried piecewise-cubic splines (20), taking the first three quartiles as interior knots.

Besides the modelling of the location parameters, i.e., fixed effects, we also model the underlying covariance structure of the data. In this regard we attempted to fit a mixed model. In our model we assume two qualitatively different sources of variation (21): random effects and serial correlation.

$$
\log \left(C_{h t}\right)=\beta_{0 i}+\beta_{1 i} T E A C H_{h}+\ldots+\varepsilon_{h t}
$$

Random variation is related to both general level variation (through the random intercept) and the variation specifically related to teaching status. In this respect we assume that there is heterogeneity between hospitals. This is postulated to be due to the effects of the unobserved variables common to all hospitals and other unobserved variables related only to teaching hospitals. Moreover, we assume that heterogeneity is not only between hospitals but also within them.

We assume the existence of a dragging effect overtime in costs, due to the factual relationship between actual costs and the final allocated budgets. However, we postulate 
that the impact of the random effects is predominant over the impact of the serial correlation effects. In fact, it is likely that the latter mainly captures the remaining heterogeneity due to misspecification, and, to a lesser degree, the actual time-varying stochastic process operating within a particular hospital.

Assuming an additive decomposition of the random variation, $\varepsilon_{\mathrm{ht}}$, into random effects $\left(\mathrm{U}_{\mathrm{h}}\right)$ and serially correlated variation $\left(\mathrm{W}_{\mathrm{h}}\right)$, we could write:

$$
\begin{aligned}
& \varepsilon_{h t}=d^{\prime}{ }_{h t} U_{h}+W_{h} \\
& d^{\prime}{ }_{h t}=\left[\begin{array}{ll}
1 & T E A C H_{h}
\end{array}\right] \\
& \beta_{0 i} \rightarrow N\left(\beta_{0}, g_{\beta 0}\right) \quad \beta_{1 i} \rightarrow N\left(\beta_{1}, g_{\beta 1}\right)
\end{aligned}
$$

The $U_{h}$ is a set of 64 mutually independent 2-element Gaussian random vectors, each of them with mean zero and covariance matrix $G\left(G=\left[\begin{array}{ll}g_{\beta 0} & g_{\beta 0 \beta 1} \mid \\ g_{\beta 1 \beta 0} & g_{\beta 1}\end{array}\right]\right)$. The $d_{h t}$ are 2element vectors of explanatory variables (intercept and $\mathrm{TEACH}_{\mathrm{h}}$ ) attached to individual measurements. The $\mathrm{W}_{\mathrm{h}}$ are sampled from 64 independent copies of a stationary process with mean zero, variance $\sigma^{2}$ (i.e., cluster variance) and correlation function $\rho(u)$, where $u$ denotes the lag between observations. For simplicity, and taking into account that we have only four time periods, we tried a first order autoregressive (or exponential) model, in which the variances were equal and the covariances decreased exponentially depending on their separation, and a compound symmetry model in which all the covariances were equal. Notice that we assume that the correlation structure is the same for all the hospitals.

The covariance matrix of $\varepsilon_{\mathrm{h}}$ is:

$$
\operatorname{Var}\left(\varepsilon_{h t}\right)=D_{h} G D^{\prime}{ }_{h}+\sigma^{2} H_{h}
$$


where $D_{h}$ is a $4 \times 2$ matrix with $\mathrm{j}$-th row $d_{h j}$ and $H_{h}$ is a $4 \times 4$ matrix with $\mathrm{j}, \mathrm{k}$-th element $h_{h j k}=\operatorname{corr}\left(W_{h}\left(t_{h j}\right), W_{h}\left(t_{h k}\right)\right)=\rho\left(\left|t_{h j}-t_{h k}\right|\right)$ with $t=(1992,1993,1994,1995)$. The correlation functions are $\rho\left(\left|t_{h j}-t_{h k}\right|\right)=\sigma^{2} \theta^{|t h j-t h k|}$ in the $\operatorname{AR}(1)$ case, and $\rho\left(\left|t_{h j}-t_{h k}\right|\right)=\theta$ in the compound symmetry model. In both cases, $\theta>0$.

Under the Gaussian assumption we assume that the covariance matrix is block diagonal (with common-zero blocks each representing the variance matrix for the vector of measurements on a single hospital). In other words, we assume that hospitals are mutually independent. The model is estimated by restricted maximum likelihood, REML (22). Given the above assumptions, this method gives unbiased, asymptotically normal and efficient estimates (21). 


\section{6.- Results.}

As shown in Table 1 costs were higher for teaching than for non-teaching hospitals. The differences were $15.49 \%$ in $1992,19.07 \%$ in $1993,21.61 \%$ in 1994 and $20.69 \%$ higher in 1995, costs being $19.21 \%$ higher in teaching hospitals on average. This difference was partially explained by the behaviour of the explanatory variables. The mean value for the case-mix index was $30 \%$ higher in teaching hospitals (1.122 vs 0.862$)$. For the remaining variables we observe the following differences: length of stay $(29.5 \%)$, visits per thousand inhabitants (24\%), daily (workdays) programmed surgical interventions per operating theatre $(22.75 \%)$ and beds per thousand inhabitants $(13.5 \%)$. For the daily urgent surgical interventions (208.25\% higher in teaching hopitals), lithotrix sessions (383.25\%) and magnetic resonances, these differences were even higher, since these activities were mainly (exclusively in one case) carried out by teaching hospitals. Finally, while the annual turnover index was higher in non-teaching hospitals $(12.3 \%)$ the differences in the neocropsy index appears to be extremely erratic (from $11 \%$ to $88 \%$ higher in teaching hospitals) to compute any mean. With the exception of 1995, differences in costs between teaching and nonteaching hospitals were increasing. This behaviour was only coincident in the case of beds, visits and daily programmed surgical interventions. Moreover, there is a monotone (with the exception of 1995) decrease in average costs in both teaching (-1.10\% from 1992 to 1993, $4.61 \%$ from 1993 to 1994 and $-0.83 \%$ from 1994 to 1995) and non-teaching hospitals (4.07 from 1992 to $1993,-6.46 \%$ from 1993 to $1994,-0.23$ from 1994 to 1995). This timevariation neither coincides with the behaviour of any of the possible explanatory variables nor with health care price index and total admissions (components of the dependent variable). The evolution of inpatient admissions may be the key factor. Finally, with the exception of magnetic resonances, the differences were not statistically significant either between teaching and non-teaching hospitals or over time. This is due to the considerable heterogeneity present in our data. Note (see Table 1 and Figures 1 and 2) that there is heterogeneity between and within hospitals, and that it appears to be higher for teaching hospitals . 
Table 2 shows the results of the estimation of the best model, in the sense of fulfilling all the usual specification and misspecification tests. We show some diagnostic plots in Figure 3 (some other results not shown can be requested to the authors). The sign of the fixed effects estimates is positive with the exception of the number of beds, the annual turnover index and daily programmed surgical interventions. Scatter plots and simple regression models corroborate these signs. The negative value for the number of beds may have to do with the fact that over the observed period NT hospitals reduced average costs per admission because of higher turnover despite the increase in the number of beds (this implies a major increase in admissions, as can be observed. For teaching hospitals the story is different: he turnover index remains constant whereas the number of beds registers a slight decrease. This implies a quasi-constant level of activity at a time when the number of beds was decreasing. In both cases this leads to a negative slope over time between average costs and hospital size. We observe significant interactions between teaching status and both case-mix and hospital activity (the annual turnover index).

Each additional day of stay increases costs by $2.21 \%$ (real average cost per admitted patient), and each magnetic resonance $0.35 \%$ (although the coefficient of the latter is only statistically significant at 90\%). This implies, given the average admission cost and the average length of stay, a marginal cost per day of stay of a $25 \%$ of its average. Because there are some symptoms of collinearity (causing an increase in the estimated standard errors) we dare to interpret those coefficients with a t-statistic higher than unity. In this respect, each visit increases costs by $6.15 \%$, each lithotrix $1 \%$ and the necropsy index $0.2 \%$. Each programmed intervention per operating theatre reduced average costs by $0.8 \%$.

The relationships between costs and beds, turnover index, urgent surgical interventions, case-mix and number of residents are not linear. Each installed bed decreases costs between 15 and $86 \%$. Likewise the turnover index reduced cost per patient (from $41 \%$ to $100 \%$ ). Urgent surgical interventions increase cost from $15 \%$ to $30 \%$ and case-mix from $52 \%$ to 90\%. The impact on costs depend of the teaching factor on the number of residents: an increase of $51.11 \%$ per resident for hospitals with fewer than 204 residents (third quartile of 
the number of residents) and $41.84 \%$ for hospitals with more than 204 residents. However, due to the considerable heterogeneity, results should be interpreted with caution. In this sense note the importance of teaching status on random variation $(0.0052$ over 0.0035$)$.

The estimated real average cost per admitted patient of a teaching hospital (evaluated at the conditional means of both the fixed and random effects) was 465096.4, with a $95 \%$ confidence interval equal to 286386.4-867867.1 (median 488942.4, first quartile 433653, third quartile 540364.9) and 427018.9 with a 95\% confidence interval equal to 317998.5573415 (median 425066.1, first quartile 384615.7, third quartile 465096.4) for a nonteaching hospital. Then, costs were estimated $9 \%$ higher (15\% in the case of median costs) in teaching than in non-teaching hospitals and the estimated dispersion was also higher among teaching hospitals. Finally, as postulated, there seems to be a dragging effect (the correlation coefficient was estimated as being equal to 0.1608 ).

\section{7. -Discussion.}

Several issues have not been raised in this paper. One of this is efficiency estimation. If one considers that inefficiency remains constant over time and it is considered a random effect, our model could be approached as a stochastic frontier version of a multiproduct hospital cost function. Alternatively, inefficiency might be disentangled from random shocks assuming, say, a half-normal distribution. A second issue is that of the assumption of a timeinvariant inefficiency. It is likely that other explanatory variables are related to data heterogeneity (complexity in particular). Thus we could have tried different functional forms in the relationship between the control variables (other than those related to teaching) and hospital costs or, for instance, we could have used other case-mix adjustment techniques.

From a health policy point of view, the only clear-cut conclusion reached here is that we cannot rely only on the case-mix adjustment for compensate the teaching factor in our 
teaching hospitals. Our estimation seems support the implementation of an even larger adjustment than that derived by former studies (18), and a clearer differentiation with regard to the size of the teaching activity.

The lack of an explicit adjustment for teaching costs in Spanish hospitals has to be seen as a clear pitfall as regards the introduction of an internal market strategy in health care or some type of simulated competition policy in health care. Who should assume the additional teaching costs or, in other words, how the education and health authorities should share the existing costs, is a different issue altogether. 
Table 1. Summary of the variables.

\begin{tabular}{|c|c|c|c|c|}
\hline \multicolumn{5}{|c|}{ Mean (Standard Deviation) } \\
\hline $\begin{array}{l}\text { Real average cost } \\
\text { per admitted patient }\end{array}$ & 1992 & 1993 & 1994 & 1995 \\
\hline Teaching hospitals & $\begin{array}{c}532737.089 \\
(179065.836)\end{array}$ & $\begin{array}{c}526872.436 \\
(165972.759)\end{array}$ & $\begin{array}{c}502581.854 \\
(147339.352)\end{array}$ & $\begin{array}{c}498409.681 \\
(157639.156)\end{array}$ \\
\hline Non teaching hospitals & $\begin{array}{l}461270.822 \\
(80865.559)\end{array}$ & $\begin{array}{l}442467.760 \\
(67237.913)\end{array}$ & $\begin{array}{l}413874.488 \\
(65671.437)\end{array}$ & $\begin{array}{l}412941.131 \\
(60877.459)\end{array}$ \\
\hline
\end{tabular}

Median (Range)

\begin{tabular}{|c|c|c|c|c|}
\hline $\begin{array}{c}\text { Real average cost } \\
\text { per admitted patient }\end{array}$ & 1992 & 1993 & 1994 & 1995 \\
\hline
\end{tabular}

\begin{tabular}{|c|c|c|c|c|}
\hline Teaching hospitals & 491677.264 & 500280.100 & 478420.745 & 491300.942 \\
& $(190896.62-$ & $(183647.16-$ & $(178306.507-$ & $(86050.33-$ \\
& $1184849.19)$ & $1132306.10)$ & $1039770.22)$ & $1040298.09)$ \\
\hline Non teaching hospitals & 452728.860 & 436088.916 & 410388.794 & 415361.167 \\
& $(314329.36-$ & $(315676.55-$ & $(307451.50-$ & $(307205.19-$ \\
& $649647.71)$ & $613262.14)$ & $592111.31)$ & $568152.83)$ \\
\hline
\end{tabular}

Mean (Standard Deviation)

\begin{tabular}{|c|c|c|c|c|}
\hline Total admissions & 1992 & 1993 & 1994 & 1995 \\
\hline Teaching hospitals & $\begin{array}{c}20298.547 \\
(11611.729)\end{array}$ & $\begin{array}{c}21002.806 \\
(11872.977)\end{array}$ & $\begin{array}{c}20976.781 \\
(11514.776)\end{array}$ & $\begin{array}{c}20604.027 \\
(11209.705)\end{array}$ \\
\hline Non teaching hospitals & $\begin{array}{c}5921.351 \\
(4738.464)\end{array}$ & $\begin{array}{c}6253.019 \\
(4746.676)\end{array}$ & $\begin{array}{c}6477.270 \\
(4802.780)\end{array}$ & $\begin{array}{c}6620.075 \\
(4724.878)\end{array}$ \\
\hline
\end{tabular}

Mean (Standard Deviation)

\begin{tabular}{|l|c|c|c|c|}
\hline Health Care Price Index & $\mathbf{1 9 9 2}$ & $\mathbf{1 9 9 3}$ & $\mathbf{1 9 9 4}$ & $\mathbf{1 9 9 5}$ \\
\hline & 100 & 102.99 & 107.70 & 112.99 \\
\hline
\end{tabular}


Table 1. (cont.)

Mean (Standard Deviation)

\begin{tabular}{|c|c|c|c|c|}
\hline Beds/1000 inhabitants & 1992 & 1993 & 1994 & 1995 \\
\hline Teaching hospitals & $\begin{array}{c}2.527 \\
(0.778)\end{array}$ & $\begin{array}{c}2.498 \\
(0.720)\end{array}$ & $\begin{array}{c}2.483 \\
(0.720)\end{array}$ & $\begin{array}{c}2.480 \\
(0.720)\end{array}$ \\
\hline Non teaching hospitals & $\begin{array}{c}2.147 \\
(0.725)\end{array}$ & $\begin{array}{c}2.170 \\
(0.693)\end{array}$ & $\begin{array}{c}2.224 \\
(0.636)\end{array}$ & $\begin{array}{c}2.249 \\
(0.653)\end{array}$ \\
\hline
\end{tabular}

Mean (Standard Deviation)

\begin{tabular}{|c|c|c|c|c|}
\hline Visits/1000 inhabitant & 1992 & 1993 & 1994 & 1995 \\
\hline Teaching hospitals & $\begin{array}{l}1298.752 \\
(380.194)\end{array}$ & $\begin{array}{l}1316.566 \\
(351.869)\end{array}$ & $\begin{array}{c}1317.982 \\
(341.438)\end{array}$ & $\begin{array}{l}1261.041 \\
(337.331)\end{array}$ \\
\hline Non teaching hospitals & $\begin{array}{c}988.173 \\
(254.809)\end{array}$ & $\begin{array}{c}1032.729 \\
(239.938)\end{array}$ & $\begin{array}{l}1081.774 \\
(230.871)\end{array}$ & $\begin{array}{l}1090.937 \\
(262.245)\end{array}$ \\
\hline
\end{tabular}

Mean (Standard Deviation)

\begin{tabular}{|c|c|c|c|c|}
\hline Length of stay (days) & 1992 & 1993 & 1994 & 1995 \\
\hline Teaching hospitals & $\begin{array}{c}9.298 \\
(1.800)\end{array}$ & $\begin{array}{c}8.999 \\
(1.464)\end{array}$ & $\begin{array}{c}8.894 \\
(1.293)\end{array}$ & $\begin{array}{c}9.286 \\
(1.364)\end{array}$ \\
\hline Non teaching hospitals & $\begin{array}{c}7.071 \\
(1.085)\end{array}$ & $\begin{array}{c}6.995 \\
(1.148)\end{array}$ & $\begin{array}{c}6.961 \\
(1.104)\end{array}$ & $\begin{array}{c}7.144 \\
(1.234)\end{array}$ \\
\hline
\end{tabular}

Mean (Standard Deviation)

\begin{tabular}{|c|c|c|c|c|}
\hline Annual turnover index & 1992 & 1993 & 1994 & 1995 \\
\hline Teaching hospitals & $\begin{array}{l}37.734 \\
(4.478)\end{array}$ & $\begin{array}{l}33.237 \\
(4.365)\end{array}$ & $\begin{array}{l}33.640 \\
(4.182)\end{array}$ & $\begin{array}{l}33.402 \\
(4.141)\end{array}$ \\
\hline Non teaching hospitals & $\begin{array}{l}35.999 \\
(6.018)\end{array}$ & $\begin{array}{c}37.509 \\
(5.158)\end{array}$ & $\begin{array}{l}38.472 \\
(4.907)\end{array}$ & $\begin{array}{l}38.913 \\
(5.072)\end{array}$ \\
\hline
\end{tabular}

Mean (Standard Deviation)

\begin{tabular}{|c|c|c|c|c|}
\hline Neocropsy index & 1992 & 1993 & 1994 & 1995 \\
\hline Teaching hospitals & $\begin{array}{c}5.183 \\
(2.944)\end{array}$ & $\begin{array}{c}4.628 \\
(2.907)\end{array}$ & $\begin{array}{c}4.261 \\
(2.958)\end{array}$ & $\begin{array}{c}3.544 \\
(2.348)\end{array}$ \\
\hline Non teaching hospitals & $\begin{array}{c}2.878 \\
(4.693)\end{array}$ & $\begin{array}{c}4.170 \\
(7.436)\end{array}$ & $\begin{array}{c}2.263 \\
(3.601)\end{array}$ & $\begin{array}{c}2.638 \\
(6.134) \\
\end{array}$ \\
\hline
\end{tabular}


Table 1. (cont.)

Mean (Standard Deviation)

Daily urgent surgical interventions

1992

\begin{tabular}{|l|l|l}
1992 & 1993 \\
\hline
\end{tabular}

\begin{tabular}{|c|c|c|c|c|}
\hline Teaching hospitals & 6.667 & 6.446 & 6.579 & 6.617 \\
& $(4.618)$ & $(4.434)$ & $(4.356)$ & $(4.482)$ \\
\hline Non teaching hospitals & 2.010 & 2.087 & 2.176 & 2.202 \\
& $(1.489)$ & $(1.550)$ & $(1.585)$ & $(1.658)$ \\
\hline
\end{tabular}

Mean (Standard Deviation)

\begin{tabular}{|l|l|l|l|l|}
\hline $\begin{array}{l}\text { Daily programmed } \\
\text { surgical interventions per } \\
\text { operating theatre } \\
\text { (workdays) }\end{array}$ & 1992 & 1993 & 1994 & 1995 \\
\hline
\end{tabular}

\begin{tabular}{|c|c|c|c|c|}
\hline Teaching hospitals & 2.605 & 2.962 & 3.089 & 2.698 \\
& $(0.679)$ & $(1.158)$ & $(1.061)$ & $(1.098)$ \\
\hline Non teaching hospitals & 2.165 & 2.363 & 2.415 & 2.290 \\
& $(0.711)$ & $(0.767)$ & $(0.674)$ & $(0.643)$ \\
\hline
\end{tabular}

Mean (Standard Deviation)

\begin{tabular}{|c|c|c|c|c|}
\hline $\begin{array}{l}\text { Daily magnetic resonances } \\
\text { (workdays) }\end{array}$ & 1992 & 1993 & 1994 & 1995 \\
\hline Teaching hospitals & $\begin{array}{r}1.059 \\
(3.279) \\
\end{array}$ & $\begin{array}{r}1.910 \\
(4.962) \\
\end{array}$ & $\begin{array}{r}2.752 \\
(6.434) \\
\end{array}$ & $\begin{array}{r}2.974 \\
(6.961) \\
\end{array}$ \\
\hline Non teaching hospitals & $\begin{array}{c}0.000 \\
(0.000)\end{array}$ & $\begin{array}{c}0.000 \\
(0.000)\end{array}$ & $\begin{array}{c}0.000 \\
(0.000)\end{array}$ & $\begin{array}{c}0.000 \\
(0.000)\end{array}$ \\
\hline
\end{tabular}

Mean (Standard Deviation)

\begin{tabular}{|c|c|c|c|c|}
\hline Daily litrotrix (workdays) & $\mathbf{1 9 9 2}$ & $\mathbf{1 9 9 3}$ & $\mathbf{1 9 9 4}$ & $\mathbf{1 9 9 5}$ \\
\hline \multicolumn{6}{|c|}{ Teaching hospitals } & 0.392 & 0.537 & 0.602 & 0.558 \\
& $(1.184)$ & $(1.395)$ & $(1.648)$ & $(1.604)$ \\
\hline Non teaching hospitals & 0.108 & 0.108 & 0.108 & 0.108 \\
& $(0.562)$ & $(0.562)$ & $(0.562)$ & $(0.562)$ \\
\hline
\end{tabular}


Table 2. REML estimates of the model.

\begin{tabular}{|c|c|c|}
\hline Variable & Coefficients & t-statistic \\
\hline \multicolumn{3}{|c|}{ Fixed effects estimates } \\
\hline \multicolumn{3}{|c|}{ Beds /1000 inhabitants } \\
\hline 0.81 to 1.91 & -0.30577 & -3.81799 \\
\hline 1.91 to 2.15 & -0.15319 & -1.85763 \\
\hline 2.15 to 2.79 & -0.81841 & -4.28262 \\
\hline$\geq 2.79$ & -0.85545 & -5.85791 \\
\hline Visits/1000 inhabitants & 6.15546 E-05 & 1.41933 \\
\hline Length of stay & 0.02209 & 2.08716 \\
\hline \multicolumn{3}{|l|}{ Annual turnover index } \\
\hline 18.58 to 31.45 & -0.49647 & -4.65436 \\
\hline 31.45 to 35.07 & -0.61989 & -7.35971 \\
\hline 35.07 to 38.112 & -1.00001 & -4.66455 \\
\hline$\geq 38.112$ & -0.41207 & -4.48885 \\
\hline Turnover index:Teaching status & 0.01274 & 2.78537 \\
\hline Neocropsy index & 0.00198 & 1.40258 \\
\hline \multicolumn{3}{|l|}{ NO urgent surgical interventions } \\
\hline 0 to 3.245 & 0.14884 & 1.42506 \\
\hline 3.245 to 6.33 & 0.30108 & 2.12972 \\
\hline$\geq 6.33$ & 0.13585 & 0.97061 \\
\hline NO programmed surgical interv. & $-7.69766 \mathrm{E}-03$ & -1.03653 \\
\hline Magnetic resonances & 3.46789 E-03 & 1.60394 \\
\hline Litrotrix & 0.01091 & 1.13684 \\
\hline \multicolumn{3}{|l|}{ Case-mix } \\
\hline 0.6058 to 1.107 & 0.51907 & 2.72769 \\
\hline$\geq 1.107$ & 0.90454 & 3.77631 \\
\hline Case-mix:teaching status & 0.49803 & 2.85593 \\
\hline \multicolumn{3}{|l|}{ Number of residents } \\
\hline 2 to 84 & 0.05814 & 0.37215 \\
\hline 84 to 204 & 0.51108 & 2.48289 \\
\hline$\geq 204$ & 0.41836 & 2.66681 \\
\hline
\end{tabular}

\begin{tabular}{|l|c|}
\hline Random effects estimates & Estimated variances \\
\hline \multicolumn{2}{|c|}{} \\
\hline Intercept & 0.01076136 \\
\hline Teaching status & 0.00520261 \\
\hline \multicolumn{2}{|c|}{0.0035354} \\
\hline Cluster residual variance & 0.1608486 \\
\hline
\end{tabular}

Restricted log-likelihood $226.1502 \quad$ Restricted AIC $\quad$-392.3004 Restricted BIC $\quad-285.9451$ 
Figure 1. Scatter plots of case-mix index and number of residents

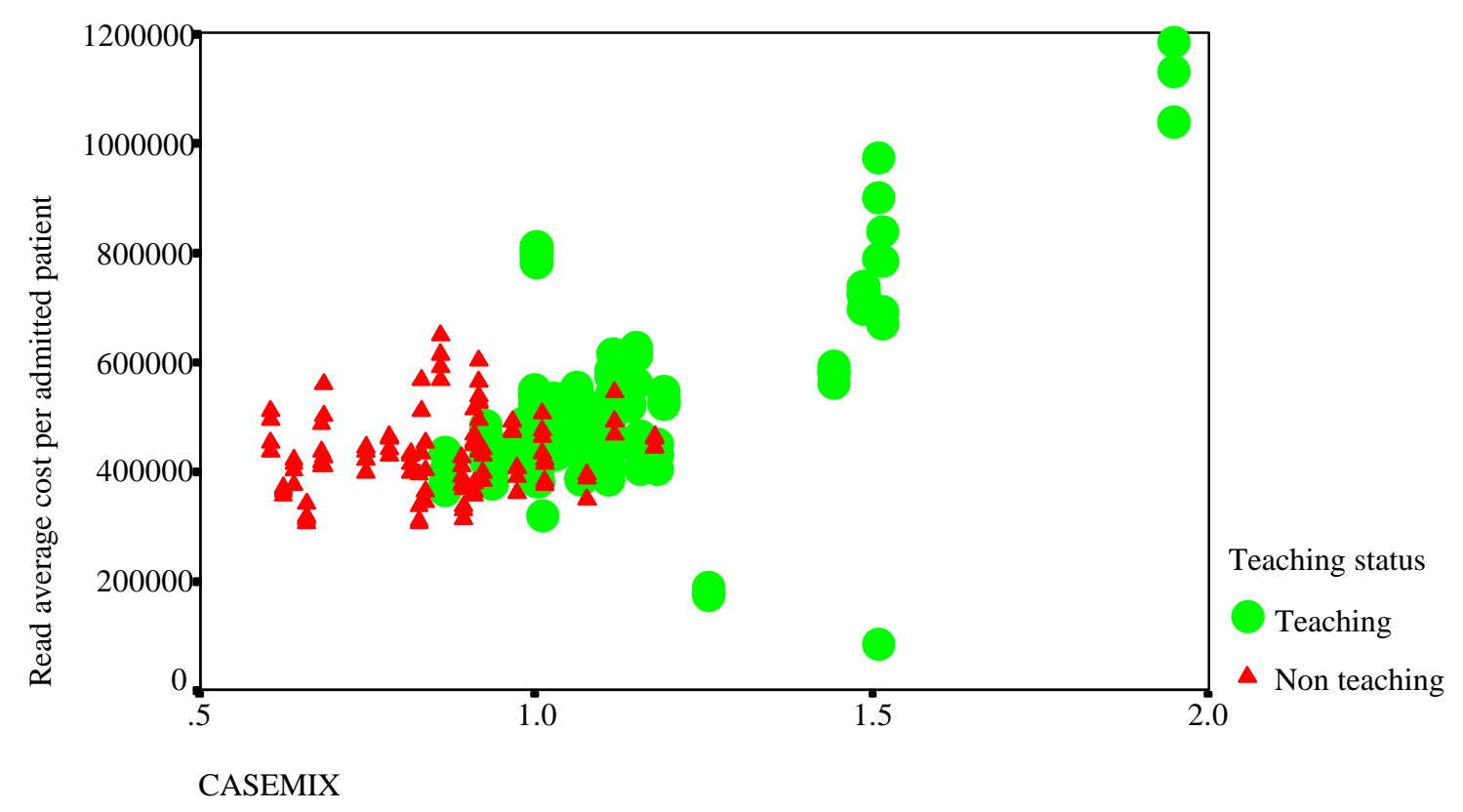

Quartiles: 0.606-0.904-1.002-1.107-1.949

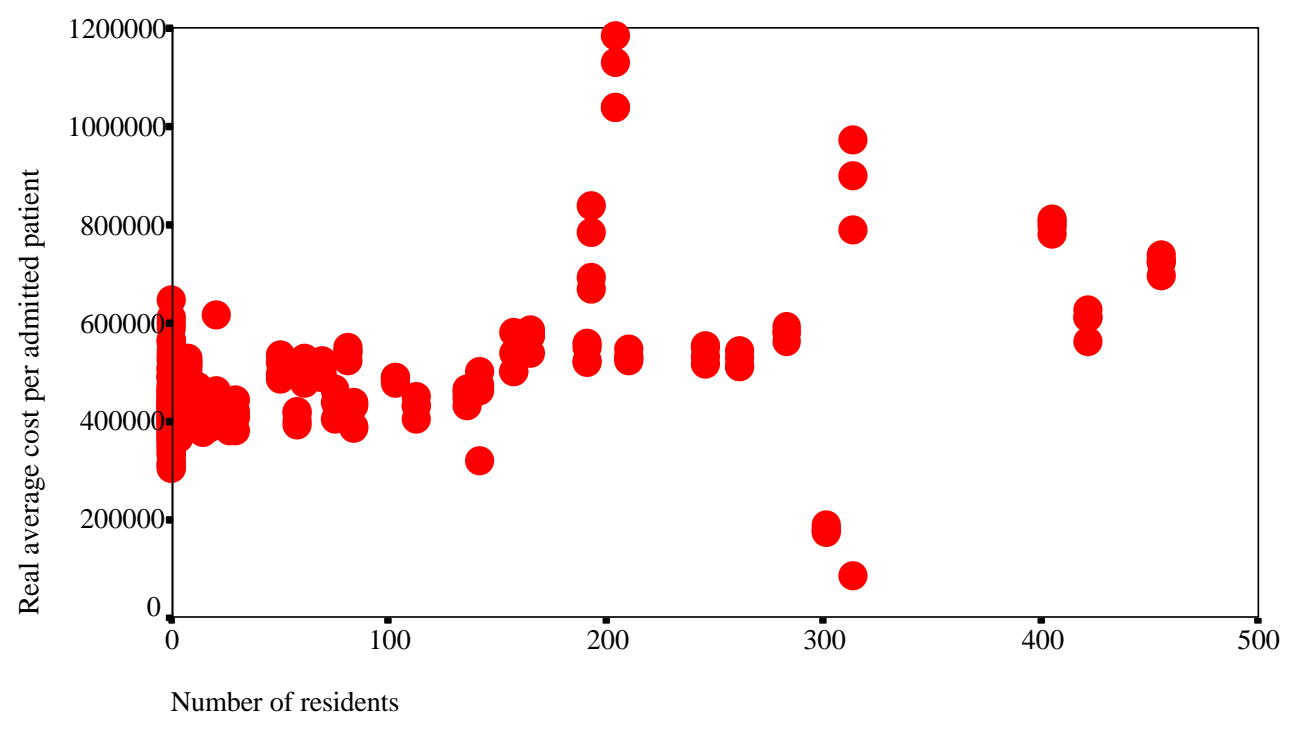

Quartiles: 2-20-84-204-455 
Figure 2. Real average cost per admitted patient. 64 INSALUD public hospitals (37 teaching; 27 non-teaching). 1992-1995.
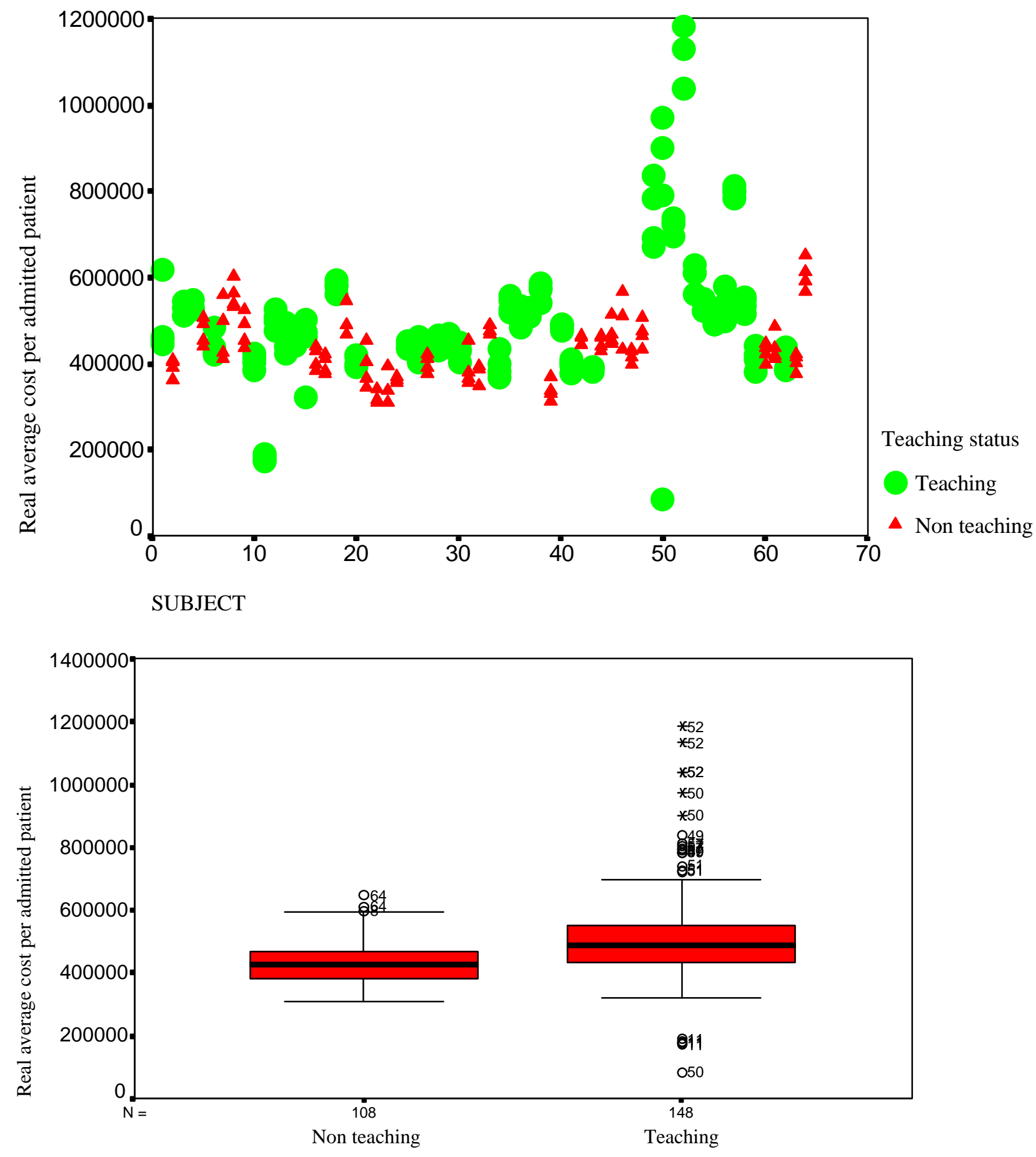

Teaching status 
Figure 3. Diagnostic plots of the mixed model.
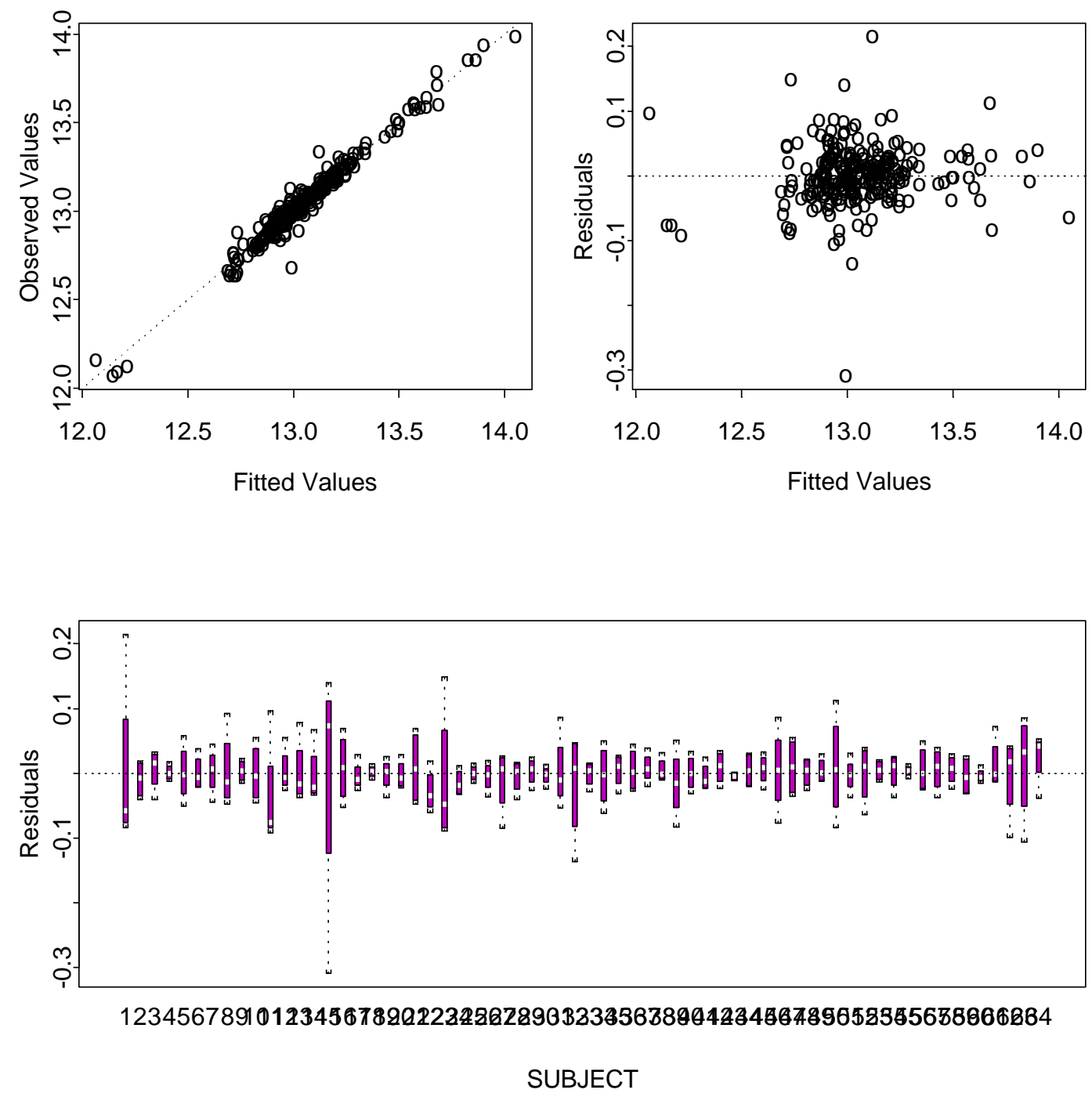


\section{References}

1. Saltman R. and Von Otter, C.V. Planned markets and public competition. Strategic reforms in Nothern European Health Systems. Buckingham:Open Univ. Press, 1992.

2. Newhouse J.P. Reimbursement under uncertainty: What to do if one cannot identify an efficient hospital. Santa Monica: RAND MR-309-hcfa, 1994.

3. Berry R.E. On grouping hospitals for Economic Analysis. Inquiry 1973; 10:5-12.

4. Vertrees J.C. and K.G. Manton. Using case-mix for resource allocation. In: Casas,M. and Wiley,M., editors. Diagnosis Related Groups in Europe. Springer Verlag, 1993.

5. Morey R.C. et al. Estimating the hospital wide-cost differentials warranted for teaching hospitals. An alternative to regression approaches. Medical Care 1995; 3(5):531-552.

6. Lehner,L.A. and Burgess,J.F. Teaching and Hospital production function. The use of regression estimates. Health Economics 1995; 4:113-125.

7. López-Casasnovas, G. Gasto público y racionalización presupuestaria. Papeles de Economia Española 1985; 23:203-213.

8. Feldstein,M.S. Economic Analysis for Health Service Efficiency: Econometric Studies of the British National Health Service. Amsterdam:North-Holland, 1967.

9. Wagstaff, A. Estimating efficiency in the hospital sector: a comparison of three statistical cost frontier models. Applied Economics 1989; 21:659-672.

10. López-Casasnovas,G. and Wagstaff,A. Competencia en Sanidad" Moneda y Crédito 
$1993 ; 196: 181-229$.

11. López-Casasnovas,G. and Wagstaff,A. La combinación de los factores productivos en el hospital: una aproximación a la función de producción. Investigaciones Económicas 1988; 12:305-327.

12. González-López Valcárcel,B. and Barber,P. Changes in public Spanish hospital efficiency after the program contracts. Investigaciones Económicas 1996; 20(3).

13. Wagstaff,A. and López-Casasnovas,G. Hospital costs in Catalonia: a stochastic frontier analysis. Applied Economic Letters 1996; 3:471-474.

14. Barer,M.L. Case mix adjustment in hospital cost analysis: Information Theory revisited. Journal of Health Economics 1982; 1(1):53-80.

15. Gaynor,M. And Anderson,G.F. Uncertainty demand and structure of hospital costs, and the cost of empty beds. Journal of Health Economics 1995; 14:291-317.

16. Culyer,A. et al. What account for the higher costs of teaching hospitals?. Soc. Econom. Administ. 1978; 12:20:30.

17. Zuckerman,S.J. et al. Measuring hospital efficiency with frontier cost functions. Journal of Health Economics 1994; 13:255-280.

18. González-López Valcárcel,B. and Barber,P. Financiación del sistema sanitario. Ajustes al pago capitativo por docencia y por asistencia sanitaria a desplazados. Mimeo. Working Paper CRES-UPF. Ministerio de Sanidad y Consumo 1997.

19. Grannemann T.W; Brown,R.S. and Pauly,M.V. Estimating hospital costs: A multiple output analysis. Journal of Health Economics 1986; 5:107-127. 
20. de Boor,C. A Practical Guide to Splines. Berlin: Springer and Verlag, 1978.

21. Diggle,P.J.; Liang,K.Y. and Zeger,S.L. Analysis of Longitudinal Data. Oxford: Oxford University Press, 1995.

22. Patterson,H.D. and Thompson,R. Recovery of inter-block information when block sizes are unequal. Biometrika 1971; 58:545-554. 